\title{
A acessibilidade e a educação: um direito constitucional como base para um direito social da pessoa com decifiência
}

Elaine Maria Bessa Rebello Guerreiro*

\section{Resumo}

Os recentes avanços na política para atendimento da pessoa com deficiência no Brasil têm aproximado várias áreas do conhecimento. Profissionais de diversos ramos (arquitetura, engenharia e direito, por exemplo) participam do debate trazendo enriquecimento para a área da educação, bem como levantando questões sobre a sua prática. Levando em consideração que a educação é um direito social e a acessibilidade é um direito constitucional, buscou-se identificar essa interface e trazer reflexões para a efetivação da inclusão escolar. A pesquisa foi feita em bibliotecas e na internet, por meio de sites governamentais e educacionais. Os documentos, leis, decretos, normas, artigos, dissertações e teses encontrados foram sistematizados a fim de subsidiar a discussão. Conclui-se que a conquista desse direito constitucional, como ferramenta para a efetivação de um direito social - a educação - é um processo que requer a participação ativa das instituições de ensino, principalmente do ensino superior, ao qual compete a formação dos profissionais que lidam com a questão, de forma direta ou indireta.

Palavras-chave: Acessibilidade; Educação Especial; Inclusão escolar.

\section{Accessibility and education: a constitutional right as a basis for a social right of person with disabilities}

\begin{abstract}
The late improvements in policies for care of people with disabilities in Brazil have drawn near many different fields of knowledge. Professionals of diverse areas (architecture, engineering and laws, for example) joined the discussion enriching the education field, but also raising questions about their practice. Taking into account the idea that education is a social right and accessibility is a constitutional right, this study sought to identify the interphase and to raise reflections for the effective school inclusion. The research was conducted in libraries and on the internet, through governmental and educational websites. The found documents, laws, decrees, norms, articles, dissertations and theses were all systemized in order to support the discussion. We have concluded that the conquer of that constitutional right, as a tool for the effective social right (in
\end{abstract}

\footnotetext{
* Professora do Instituto Federal de Educação, Ciência e Tecnologia do Amazonas (IFAM), Amazonas, Brasil.
} 
this case, education), is a process that requires active participation of educational institutions - mainly higher education institutions, which are responsible for the education of professionals who deal with the matter, either directly or indirectly.

Keywords: Accessibility; Special education; Inclusive schools.

\title{
Introdução
}

A educação visa à formação integral do ser humano, sendo um processo contínuo de integração à sociedade em todo o curso de sua vida. Ela faz parte dos direitos fundamentais do homem, das necessidades básicas de todos, conforme é estabelecido na Declaração dos Direitos Humanos (ONU, 1948), nos itens 1,2 e 3 do Art. $26^{\circ}$. De acordo com os princípios estabelecidos nessa declaração, deve-se considerar que

\begin{abstract}
Entender a educação como direito humano diz respeito a considerar que as pessoas se diferenciam dos outros seres vivos por uma característica única do ser humano: a habilidade de produzir conhecimento e, por meio dele, transformar, organizar-se e rever valores. Nesse sentido, fica claro que a educação tem um papel fundamental para criar uma cultura de respeito à vida e à dignidade humana, combatendo preconceitos e a discriminação. (BRASIL/SEDH 2008, p. 2)
\end{abstract}

A educação foi positivada em nossa constituição como um direito social, sendo um dever do Estado e da família. De acordo com Martins Filho (1999), os Direitos Sociais, dentro do quadro dos Direitos Fundamentais, inserem-se nos "direitos positivos", que são responsabilidade do Estado ou do particular. Os direitos são concedidos aos indivíduos e as garantias são preceitos que viabilizam tais direitos (ABREU, 2001).

A Lei n. 9.394/96 (BRASIL, 1996) diz, no Art. $1^{\circ}$, que a educação abrange os processos formativos desenvolvidos na vida familiar, no convívio humano, no trabalho, nas instituições de ensino e pesquisa, nos movimentos sociais e organizações da sociedade civil e nas manifestações culturais. Para os educandos com necessidades educacionais especiais esta lei nos diz, no Art. $58^{\circ}$, que a Educação Especial é uma modalidade de educação escolar oferecida preferencialmente na rede regular de ensino.

A Educação Especial perpassa todos os níveis e etapas do sistema educacional brasileiro, sendo ofertada ao aluno com deficiência, transtornos globais do desenvolvimento e altas habilidades/superdotação, conforme estabelece o documento da Política Nacional de Educação Especial na Perspectiva da Educação Inclusiva (BRASIL, 2008). Deve ser transversal desde a educação infantil até a educação superior, e tem como objetivo assegurar a inclusão escolar de seu alunado específico, orientando os sistemas de ensino para garantir, 
entre outros aspectos, a acessibilidade arquitetônica nos transportes, nos mobiliários, nas comunicações e na informação.

O direito à educação pressupõe a participação plena do aluno com algum tipo de deficiência no ambiente escolar, ou seja, em todas as atividades pedagógicas, esportivas ou de lazer. Sendo a escola um ambiente público, fora do domicílio do aluno, este precisa deslocar-se até esse outro espaço, esse outro ambiente. Existem também os deslocamentos internos, seja em um prédio escolar ou em um campus universitário. Tais deslocamentos se fazem no tempo e no espaço, sendo compartilhados com todos os que precisam fazer esse mesmo percurso para realizar suas atividades diversas. Temos, então, um direito social (a educação) que demanda outros direitos para que possa ser efetivado. Neste caso, tem-se a acessibilidade física, que é um direito constitucional, como uma necessidade para que se possa usufruir de um direito social.

Considerando o exposto, o objetivo deste trabalho é refletir sobre a importância da acessibilidade no ambiente educacional para a efetivação da inclusão escolar. Para isto foi realizado um levantamento da legislação brasileira que trata da temática em questão, bem como de estudos sobre a acessibilidade no ambiente educacional. Portanto, é uma pesquisa bibliográfica e documental realizada por meio da internet e de bibliotecas.

\section{Resultados}

Os documentos, leis, decretos, normas, artigos, dissertações e teses estudados para este trabalho foram sistematizados a fim de subsidiar a discussão. Desta forma surgiram quatro grupos, que são: conceito e definição; antecedentes históricos da questão da acessibilidade; contexto legal da acessibilidade na legislação brasileira; e acessibilidade no ambiente educacional.

\section{Conceito e definição}

Erhardt (2009) faz distinção entre os termos conceito e definição. Segundo ele, conceito é a abstração do que não é essencial para se construir uma identidade, ou seja, uma apreensão da essência de determinado objeto. Já definição é a delimitação dos elementos do conceito, a exteriorização da apreensão mental mediante palavras. Nader (2001), em seu livro Filosofia do Direito, diz que a definição é juízo externo enquanto conceito é juízo interno.

Para Roy (2005), o conceito de acessibilidade como uma das diversas condições do "acesso universal" é o que pode gerar maior confusão em razão dos interesses e necessidades diversos de quem dele se utiliza. A acessibilidade pode se referir a conectividade, meios econômicos, infraestrutura, meios cognitivos e educação, disponibilidade de informação, usabilidade etc. Com o advento da sociedade da informação, ela deixa de ser focada no espaço físico e passa a incorporar o ciberespaço. ${ }^{1}$ 
A Lei no 10.098, de 19 de dezembro de 2000, (BRASIL, 2000) define acessibilidade como a possibilidade e a condição de alcance para a utilização com segurança e autonomia dos espaços, mobiliários e equipamentos urbanos, das edificações, dos transportes, dos sistemas e também dos meios de comunicação pela pessoa portadora de deficiência ou com mobilidade reduzida (I do Art. $2^{\circ}$ ). O objetivo dessa lei é estabelecer normas gerais e critérios básicos para a promoção da acessibilidade das pessoas com deficiência ou com mobilidade reduzida.

A ABNT NBR 9050 (ABNT, 2004), que trata da Acessibilidade a edificações, mobiliário, espaços e equipamentos urbanos, define acessibilidade como a "possibilidade e condição de alcance, percepção e entendimento para a utilização com segurança e autonomia de edificações, mobiliário, equipamento urbano e elementos" (Id. Ibid., p.10).

Já o Decreto-lei n 5.296, de 2 de dezembro de 2004 (BRASIL, 2004), que regulamenta as Leis $n^{\circ} 10.048$ e 10.098/00, no capítulo das condições de acessibilidade, diz que "se considera acessibilidade como sendo a condição para utilização, com segurança e autonomia, total ou assistida, aos espaços mobiliários e equipamentos urbanos, às edificações, aos serviços de transporte, aos sistemas e meios de comunicação e informação, por pessoas com deficiência ou com mobilidade reduzida". Observa-se que no texto não aparece a palavra "definição" ou "define", apenas se diz que "se considera". No entanto, além de regulamentar a Lei no 10.098/00, este Decreto tem como referência básica as normas de acessibilidade da ABNT, nas quais é definido o termo acessibilidade.

Em uma breve análise do que é definido por acessibilidade nesses três documentos, observam-se similaridades entre eles e também a ampliação do termo. Na Lei $n^{\circ}$ 10.098/00 pode-se encontrar a definição de acessibilidade indicando o ambiente, o sistema e o meio que deve estar acessível, a condição de uso e a quem se dirige. Na NBR 9050/2004 se encontram as mesmas condições, porém foram introduzidos os termos percepção e entendimento (de quem se utiliza), mas não foi especificado a quem se dirige, pois seu parâmetro básico é o desenho universal. O Decreto-lei n ${ }^{0} 5.296 / 04$ amplia a definição encontrada nos documentos anteriores quando introduz o termo "total ou assistida" ao se referir à condição de utilização.

Voltando à distinção que Nader (2001) faz entre conceito e definição, a acessibilidade pode ser entendida sob diversos olhares (conceito ou juízo interno), sendo necessária uma delimitação do termo, mediante palavras, para que ele possa ser operacionalizado. Desta forma, a definição adotada no Decreto-lei n 5.296/04 identifica os marcos (limites), qual sua condição, o meio e a quem se destinam. A condição de utilização é a sua "usabilidade", no sentido de que é algo que se torna concreto quando posto em prática. 


\section{Antecedentes históricos da questão da acessibilidade}

De acordo com Costa, Maior e Lima (2005), a questão da acessibilidade para a pessoa com deficiência começou a fazer parte das políticas públicas há pouco tempo. A discussão sobre os direitos da pessoa com deficiência tem seu fundamento nos direitos humanos e na cidadania, fruto da Declaração Universal dos Direitos Humanos de 1948 (ONU, 1948). Segundo Feijó (2008), antes da $2^{\text {a }}$ Guerra Mundial, os direitos humanos tinham influência somente dentro dos Estados, mas a partir do fim da guerra, houve uma preocupação em internacionalizar os direitos fundamentais do homem. Com essa internacionalização surgiram vários documentos que visavam efetivar tal conquista (FEIJÓ, 2008).

A Declaração Universal dos Direitos Humanos (ONU, 1948), como ideal comum a ser alcançado por todos os povos e nações, é um dos documentos básicos das Nações Unidas. Em seu preâmbulo, convida todos os indivíduos e órgãos da sociedade a se empenhar no seu cumprimento, por meio do ensino e da educação. Este destaque é importante, visto que é através da educação que o indivíduo e a sociedade podem alcançar o progresso social e também melhor condições de vida, como almeja essa declaração. De acordo com Atique e Veltroni (2007), a maioria das nações tem a educação como um dos seus alicerces fundamentais, com uma posição-chave na infraestrutura da sociedade. Para esses autores, uma sociedade só será considerada desenvolvida quando garantir a inserção das pessoas com deficiência no sistema educacional. A declaração mencionada diz, no seu Art. $1^{\circ}$, que todos os homens nascem livres e iguais em dignidade e direito.

Segundo Bernardo (2006), o princípio da dignidade da pessoa humana foi positivado na maioria das Constituições do pós-guerra e na Declaração Universal das Nações Unidas. Ele afirma que esse princípio foi positivado pela nossa Constituição da República de 1988 (BRASIL, 1988), que o elencou como fundamento, criando uma verdadeira cláusula geral de tutela da pessoa humana. Atique e Veltroni (2007) confirmam que a positivação constitucional dos direitos da pessoa com deficiência foi conquistada como fruto de uma evolução histórica, interagindo com os Direitos Humanos e com a cidadania. Para esses autores, somente a positivação não basta, sendo necessária a garantia de seu efetivo exercício.

De acordo com Aceti (2007), o que se almeja não é assegurar a aparente igualdade (física ou psicológica), mas sim assegurar a igualdade das coisas, das oportunidades, do acesso (desde a locomoção até a comunicação) e dos meios de informação e ensino. A liberdade de ir e vir fica impossibilitada no momento em que o acesso a um determinado ambiente possui uma barreira física ou de comunicação. Quando isto acontece, impede-se alguém de usufruir desse ambiente, gerando um processo discriminatório (ACETI, 2007). 
A Declaração dos Direitos das Pessoas Deficientes foi aprovada pela Assembléia Geral da Organização das Nações Unidas, em 9 de novembro de 1975 (ONU, 1975). Seu objetivo foi promover os mais altos padrões de vida, o pleno emprego e condições de desenvolvimento e progresso econômico e social dos Estados Membros das Nações Unidas. Segundo Bobbio (1992), com essas conquistas da universalização e multiplicação dos direitos humanos, o homem passa a ser visto na sua especificidade e concreticidade, como: gênero (homem e mulher), fases da vida (criança, adulto, idoso), normal e excepcional (doentes, deficientes etc.). Para Feijó (2008), esse foi o momento em que os direitos das pessoas com deficiência tomaram vulto e passaram a ser desejáveis. Para que as deliberações da ONU fossem executadas nas Américas, a Organização dos Estados Americanos criou a Década das Américas pelos Direitos e pela dignidade das Pessoas com Deficiência, de 2006 a 2016, que teve como lema igualdade, dignidade e participação.

\section{O contexto legal da acessibilidade na legislação brasileira}

Antes da nossa atual Constituição, o tema acessibilidade havia sido tratado na Emenda Constitucional no 12, de 17 de outubro de 1978 (BRASIL, 1978). Nesta é assegurada à pessoa com deficiência a melhoria de sua condição social e econômica, mediante, entre outros itens, a possibilidade de acesso a edifícios e logradouros públicos.

O item 2 do Art. $227^{\circ}$ da Constituição Federal de 1988 (BRASIL, 1988) diz que a lei disporá sobre as normas para a construção de logradouros, a fim de garantir o acesso adequado às pessoas com deficiência. E, no Art. 244, também é prevista a adaptação dos logradouros públicos, com a mesma finalidade. Segundo Aceti (2007), possibilitar o acesso irrestrito aos espaços públicos, a fim de garantir a plenitude desse exercício às pessoas com deficiência, é função do Estado.

Ao falar sobre o movimento de inclusão, Fávero (2007, p. 38) diz que a nossa Constituição não prevê um simples "abrir de portas e adapte-se quem puder", mas impõe o dever de promover e de realizar ações que garantam a não exclusão.

As legislações infraconstitucionais foram consolidando os avanços decorrentes desse novo status que a pessoa com deficiência tem alcançado. $O$ Decreto-lei $n^{\circ}$ 5.296/04, que regulamenta as Leis $n^{\circ} 10.048 / 00$ e 10.098/00, sendo esta última a que estabelece normas gerais e critérios básicos para a promoção da acessibilidade, diz no Art. 24 que

Os estabelecimentos de ensino de qualquer nível, etapa ou modalidade, públicos ou privados, proporcionarão condições de acesso e utilização de todos os seus ambientes ou compartimentos para pessoas portadoras de deficiência ou com mobilidade reduzida, inclusive 
salas de aula, biblioteca, auditórios, ginásios e instalações desportivas, laboratórios, áreas de lazer e sanitários. (BRASIL, 2004)

A Convenção dos Direitos das Pessoas com Deficiência (BRASIL, 2007), em seu Art. $9^{\circ}$, trata da Acessibilidade que tem por fim possibilitar às pessoas com deficiência viver com autonomia e com plena participação em todos os aspectos de sua vida. No Brasil, esta Convenção foi promulgada pelo Decreto $n^{\circ} 6.949$, de 25 de agosto de 2009 (BRASIL, 2009).

A Política Nacional de Educação Especial no contexto da Educação Inclusiva (BRASIL, 2008), tem como objetivo assegurar a inclusão escolar de seu alunado específico e orientar os sistemas de ensino, entre outros itens, a acessibilidade urbanística, arquitetônica, nos mobiliários e equipamentos, nos transportes, na comunicação e informação. Para que isso ocorra, fazem-se necessárias ações que envolvem o planejamento e a organização de recursos e serviços para a promoção da acessibilidade arquitetônica nas comunicações, nos sistemas de informação, nos materiais didáticos e pedagógicos, que devem ser disponibilizados desde os processos seletivos, bem como no desenvolvimento de todas as atividades que envolvem o ensino, a pesquisa e a extensão. A palavra acessibilidade está inserida no texto dessa política educacional, tanto para as questões arquitetônicas quanto para as formas de comunicação e informação, materiais didáticos e pedagógicos.

Por meio do Decreto $\mathrm{n}^{\circ} 7.611$, de 17 de novembro de 2011, é previsto a estruturação de núcleos de acessibilidade nas instituições federais da educação superior, cujo objetivo é eliminar as barreiras físicas, de comunicação e de informação que restringem a participação e o desenvolvimento acadêmico e social do aluno com deficiência. Nesse mesmo dia foi promulgado o Decreto ${ }^{\circ}$ 7.612, que institui o Plano Nacional dos Direitos da Pessoa com Deficiência Plano Viver sem Limite. Esse plano possui quatro eixos de atuação, que são: acesso à educação; atenção à saúde; inclusão social; e acessibilidade. A acessibilidade, além de ser um eixo, permeia os outros três, tanto de forma física, como de comunicação e afetividade.

A Política Nacional de Humanização (BRASIL, 2006) propõe o conceito de ambiência utilizado aqui, como "espaço físico entendido como espaço social, profissional e de relações interpessoais que deve proporcionar atenção acolhedora, resolutiva e humana" (p. 5). Ou seja, o espaço é mais abrangente que a mera quantificação em metros quadrados ou localização, para incorporar, também, as questões deste ambiente como facilitador do processo educativo e das relações interpessoais. Essa dimensão, que pode facilitar ou dificultar o êxito acadêmico, passa pela possibilidade de se transpor as barreiras arquitetônicas, urbanísticas, de comunicações e atitudinais, vivenciadas.

Para Tuan (apud DUARTE; COHEN, 2004), os espaços se transformam em lugares quando permitem que as pessoas desenvolvam afetividade em 
relação a este local, e esta atividade só é possível por meio da experiência do espaço. Mesmo para a questão isolada da acessibilidade arquitetônica, embora esta não faça parte do processo de ensino-aprendizagem, ela tem um significado estrutural (acesso físico) e um significado emocional/afetivo.

\section{Acessibilidade no ambiente educacional}

Quando o espaço não é vivenciado, representa uma barreira ao relacionamento que, para Duarte e Cohen (2006; 2003), em muitos casos, pode ser pior que os obstáculos físicos. Desta forma, propuseram que todos os espaços acadêmicos deveriam ser democráticos, no sentido de serem compreendidos e utilizados por todos, cabendo à direção da instituição criar e/ou disponibilizar as soluções técnicas adequadas para que este objetivo fosse alcançado. A consideração dessas características das pessoas com dificuldades de locomoção não devem ser ditadas por razões de solidariedade, mas por uma concepção de sociedade na qual se entende que todos devem participar com direito de igualdade (DUARTE; COHEN, 2004).

Experienciar os espaços permite, à pessoa com deficiência visual, por exemplo, estímulos de memória e de organização espaço-temporal que irão lhe proporcionar maior interação social (SANTOS, 1998). De acordo com Duarte e Cohen (2004), espaços inclusivos são aqueles que permitem que todos, inclusive as pessoas com deficiência, experienciem tais espaços com segurança, competência e liberdade, estabelecendo uma relação harmoniosa da pessoa com o mundo exterior.

Aranha (2004) diz que a acessibilidade física é um dos primeiros requisitos para a universalização do ensino, pois quando ela não é disponibilizada, não se pode garantir a educação para todos. Nesta mesma linha de raciocínio, Manzini e Corrêa (2008) destacam que a acessibilidade facilita a inclusão social, pois o meio pode causar ou agravar as condições de desvantagens vivenciadas pelas pessoas com deficiência. Rodrigues (2004) trouxe reflexões sobre o acesso e suas representações em nossa cultura. Para ele, as barreiras arquitetônicas precisam ser vistas não apenas como um conjunto de rampas e dimensões a serem respeitadas, mas como uma filosofia de acolhimento, conforto e facilidade, em todos os espaços dos edifícios.

Audi e Manzini (2006) desenvolveram o Protocolo para avaliação de acessibilidade em escolas do ensino fundamental: um guia para gestores e educadores, que foi utilizado na pesquisa de Manzini e Corrêa (2008). Esse protocolo também foi utilizado por Corrêa e Manzini (2011) em escolas de educação infantil de uma cidade do interior de São Paulo para fins de auxílio na identificação de parâmetros nacionais para promover ambientes acessíveis.

Duarte e Cohen (2006) propuseram uma metodologia de avaliação da acessibilidade aos espaços no ensino fundamental, pois, segundo essas autoras, o espaço construído tem um papel fundamental na superação das desigualdades 
físicas e sociais nas inter-relações humanas. Manzini e Corrêa (2008), através do Grupo de Pesquisa Deficiências Físicas e Sensoriais da Faculdade de Filosofia e Ciências da Unesp, Campus de Marília, propuseram uma avaliação da acessibilidade em escolas do ensino fundamental, com o intuito de contribuir para ações de modificações/adaptações do ambiente escolar menos restrito.

Mas não basta a possibilidade de acesso e permanência no mesmo espaço físico para que haja inclusão. Em seu relato de pesquisa sobre as mudanças ocorridas nas escolas para a implantação da inclusão escolar, Leonardo, Bray e Rossato (2009) constataram os seguintes dados quanto aos tipos de adaptações realizadas: alterações quanto ao espaço físico (42,8\%), mudanças na forma de trabalho (14,3\%), conscientização da comunidade interna e externa $(4,8 \%)$, contratação de profissionais especializados $(4,8 \%)$, adaptações físicas já durante a construção (33,3\%). Como pode ser observado, pelos percentuais indicados, as intervenções físicas foram maiores que as pedagógicas e de capacitação. Não basta construir rampas ou outros elementos da acessibilidade para uma efetiva inclusão escolar, pois esta requer um conjunto de condições de ordem pedagógica, de capacitação e de gestão.

Marins e Matsukura (2009) avaliaram as ações implementadas, a partir das diretrizes nacionais para a educação inclusiva na rede regular de ensino, em seis escolas do ensino fundamental das cidades-polo do Estado de São Paulo. O espaço físico foi um dos itens elencados e, das seis escolas avaliadas, todas informaram possuírem alguns tipos de adaptações ou construções visando à acessibilidade de seus alunos. Os principais elementos listados foram rampas, corrimão, elevadores, banheiros adaptados e marcadores para pessoas com deficiência visual. Porém não é informado no artigo se essas construções, ou adaptações, estavam de acordo com as normas da NBR 9050:2004 da ABNT.

Mazzoni et al. (2000) discutiram a acessibilidade, tanto no espaço físico quanto no espaço digital, em um ambiente de biblioteca na Universidade Federal de Santa Catarina - UFSC. Foi feito um breve histórico sobre o movimento em prol da acessibilidade e sua evolução, assinalando que sua origem foi no início dos anos 60, nos Estados Unidos e na Europa. Do conceito de projetos livres de barreira no espaço físico, chegou-se ao desenho para todos. Para esses autores, a acessibilidade é parte das condições especiais a que as pessoas com deficiência têm direito, mas não se constitui num ambiente segregado e exclusivo para a pessoa com deficiência.

Emmel e Castro (2003) mapearam, em 1999, as barreiras arquitetônicas existentes em 48 prédios do campus-sede da Universidade Federal de São Carlos - UFSCar, bem como a população (docente, discente e administrativa) com deficiência ou mobilidade reduzida. Nesse estudo, além do mapeamento das barreiras, foram feitas sugestões de melhoria no ambiente físico, principalmente no restaurante universitário e biblioteca, por serem os locais mais indicados com problemas de acessibilidade. 
Manzini, et al. (2003) realizaram um mapeamento e quantificação de barreiras físicas para pessoas com deficiência nos prédios da Faculdade de Filosofia e Ciências da Unesp/Marília. Os autores concluíram que ainda são necessárias várias adaptações estruturais, propondo mudanças, de acordo com a NBR 9050, em forma de projeto arquitetônico. Bittencourt et al. (2004), por meio de um projeto de extensão, realizaram um diagnóstico sobre a situação do Campus A. C. Simões, da Universidade Federal de Alagoas - UFAL, bem como propuseram soluções para os problemas encontrados.

Chahini (2005), na sua dissertação de mestrado sobre os desafios do acesso e permanência de pessoas com deficiência no ensino superior, relata várias dificuldades encontradas pelos alunos, em relação, por exemplo, à estrutura física da universidade, como a falta de rampas e elevadores.

Perini (2006), em seu estudo sobre o processo de inclusão no ensino superior, do ponto de vista dos alunos, relata também problemas com a estrutura física dos prédios, entre outras dificuldades. Pellegrini (2006) também relata as dificuldades com a infraestrutura encontradas por alunos na Universidade Federal de Santa Maria - UFSM.

Andrade, Pacheco e Farias (2007), destacaram a questão da acessibilidade física e as normas da ABNT a serem observadas nas instituições de nível superior. Pereira (2007) estudou a inclusão no ensino superior de alunos com deficiência que entraram pela reserva de vagas, identificando também problemas com a estrutura física da universidade.

Ferreira (2007) relatou a experiência do Programa de Acompanhamento ao Estudante com Necessidades Especiais - PROENE, na Universidade Estadual de Londrina - UEL. Entre várias ações do programa, encontra-se o assessoramento na adequação e funcionalidade dos projetos ou reformas, tanto nas dependências da UEL quanto em prédios sob sua responsabilidade, visando à eliminação de barreiras físicas e arquitetônicas.

Lamônica et al. (2008) realizaram um estudo, na Universidade de São Paulo - USP, Campus de Bauru, com o objetivo de identificar, descrever e mapear as barreiras físicas nessa instituição, durante o período de 2001 a 2005. Todos esses estudos tratam do diagnóstico em relação às condições de acessibilidade, tanto arquitetônicas quanto urbanísticas.

Rosseto (2009) em sua tese de doutorado, que teve como objetivo ouvir histórias das trajetórias de pessoas com deficiência no ensino superior, apresenta relatos que abordam situações de desvantagens com relação às barreiras arquitetônicas, à falta de materiais adaptados e de professores capacitados para atendê-los, entre outras coisas. 


\section{Conclusão}

Este estudo apontou para um aumento da legislação que trata das questões de acessibilidade para a pessoa com deficiência, como também para o crescimento dos estudos nos espaços educacionais, tanto do ensino básico como no superior. Aponta, também, que não basta a adequação desse espaço para que a inclusão escolar ocorra, é preciso que haja, igualmente, as adequações dos recursos pedagógicos e a capacitação do corpo docente e gestor. Considerando que a acessibilidade não se refere apenas à estrutura física de uma instituição de ensino, pois envolve também a comunicação, o transporte, os recursos didáticos e tecnológicos, há muito que avançar. Esse avanço deve ser feito por toda a sociedade, no entanto, as instituições de ensino, por suas características e função, devem ser mediadoras do processo. Ou seja, a conquista desse direito constitucional como ferramenta para a efetivação de um direito social, que é a educação, é um processo que requer a participação ativa das instituições de ensino, enfatizando-se o ensino superior, ao qual compete a formação dos profissionais que lidam com a questão, de forma direta ou indireta.

\section{Referências}

ABREU, N. M. C. Os Direitos Fundamentais na Constituição Federal de 1988. [2001]. Disponível em: <http://www.passeja.com.br/file/download/ Os_direitos_fundamentais_na_constituicao.pdf >. Acesso em: 9 jun. 2011.

ACETI, D. C. S. O amparo legal aos portadores de necessidades especiais. Anuário de Produção Acadêmica Docente - ANUDO, v. 1, n. 1, p. 207-214, 2007. Disponível em: <http://sare.unianhanguera.edu.br/index.php/anudo/issue/view/35/ showToc>. Acesso em: 31 mar. 2011.

ANDRADE, M. S. A.; PACHECO, M. L.; FARIAS, S. S. P. Pessoas com deficiência rumo ao processo da inclusão na educação superior. Rev. Conquer, v. 1., 2006. Disponível em: <http://www.fasb.edu.br/revista/index.php/conquer/article/view/ 27/9>. Acesso em: 1 set. 2011.

ARANHA, M. S. F. Educação inclusiva - Referenciais para a construção de sistemas educacionais Inclusivos: a escola. Brasília: MEC/Secretaria de Educação Especial, 2004. v. 3.

ASSOCIAÇÃO BRASILEIRADE NORMAS TÉCNICAS -ABNT. NBR 9050: acessibilidade a edificações, mobiliário, espaços e equipamentos urbanos. Rio de Janeiro, 2004.

ATIQUE, A. L. V.; VELTRONI, A. L. O direito à educação no Brasil e a pessoa portadora de deficiência: as obrigações das instituições de ensino superior. NEJ, v. 12, n. 1, p. 119-135, jan./jun. 2007.

AUDI, E. M. M.; MANZINI, E. L. Protocolo para avaliação de acessibilidade em escolas do ensino fundamental: um guia para gestores e educadores. Marília: ABPEE, 2006. 
BITTENCOURT, L. S. et al. Acessibilidade e cidadania: barreiras arquitetônicas e exclusão social dos portadores de deficiência física. In: CONGRESSO BRASILEIRO DE EXTENSÃO UNIVERSITÁRIA, 2, Belo Horizonte, 2004. Anais... Belo Horizonte: UFMG, 2004. Disponível em: <http://www.ufmg.br/congrext/Direitos/Direitos10.pdf>. Acesso em: 1 abr. 2011.

BERNARDO, W. O. L. O princípio da dignidade da pessoa humana e o novo direito civil: breves reflexões. Rev. da Faculdade de Direito de Campos, Ano VII, n. 8, jun. p. 229-267. 2006. Disponível em: <http://www.fdc.br/Arquivos/ Mestrado/Revistas/Revista08/Artigos/WesleyLousada.pdf>. Acesso em: 26 mai. 2011.

BOBBIO, N. A era dos direitos. Rio de Janeiro: Campus, 1992.

BRASIL. Constituição da República Federativa do Brasil, de 5 de outubro de 1988. Disponível em: <http://www.planalto.gov.br/ccivil_03/constituicao/ constitui\%C3\%A7ao.htm>. Acesso em: 9 jun. 2011.

BRASIL. Convenção sobre os direitos das pessoas com deficiência. Brasília: SEDH/CORDE, 2007. Disponível em: <http://portal.mec.gov.br/> Acesso em: 31 mar. 2011.

BRASIL. Decreto-lei no 5.296, de 2 de dezembro de 2004. Diário Oficial da União [da] República Federativa do Brasil, Brasília, DF, 26 ago. 2009. Seção 1 , p. 3.

BRASIL. Decreto $n^{\circ} 6.949$, de 25 de agosto de 2009. Promulga a Convenção Internacional sobre os Direitos das Pessoas com Deficiência e seu Protocolo Facultativo, assinados em Nova York, em 30 de março de 2007. Diário Oficial [da] República Federativa do Brasil, Brasília, DF, 26 ago. 2009. Seção 1, p. 3.

BRASIL. Decreto no 7.611, de 17 de novembro de 2011. Dispõe sobre a educação especial, o. Diário Oficial da União [da] República Federativa do Brasil, Brasília, DF, 18 nov. 2011. Seção 1, p. 12.

BRASIL. Decreto $n^{0} 7.612$, de 17 de novembro de 2011. Institui o Plano Nacional dos Direitos da Pessoa com Deficiência - Plano Viver sem Limite. Diário Oficial da União [da] República Federativa do Brasil, Brasília, DF, 18 nov. 2011. Seção 1, p. 12-13.

BRASIL. Direito a Educação, Direito ao Trabalho e à Seguridade Social (Módulo V). In: Direitos Humanos e Mediação de Conflitos. Brasília: SEDH/ITS Brasil, 2008.

BRASIL. Emenda Constitucional n. 12, de 17 de outubro de 1978. Diário Oficial [da] República Federativa do Brasil, Brasília, 19 outubro 1978. Seção 1, p. 16857. 
BRASIL. Lei n. 9.394, de 20 de dezembro de 1996. Estabelece as diretrizes e bases da educação nacional.<http://portal.mec.gov.br/seed/arquivos/pdf/tvescola/ leis/lein9394.pdf> Acesso em: 1 set. 2011.

BRASIL. Lei n 10.098, de 19 de dezembro de 2000. Diário Oficial [da] República Federativa do Brasil, Brasília, DF, 20 dezembro 2000. Seção 1, p. 2.

BRASIL. Política nacional de Educação Especial na perspectiva da Educação Inclusiva. Brasília: MEC/SEESP, 2008. Disponível em: <http:// portal.mec.gov.br/seesp/arquivos/pdf/politica.pdf>. Acesso em: 30 mar.2011.

CHAHINI, T. H. C. Os desafios do acesso e permanência de pessoas com necessidades educacionais especiais nas instituições de educação superior de São Luiz - MA. 2005. 201 f. Dissertação (Mestrado em Educação) - Universidade Federal do Maranhão, São Luiz, 2005.

CORRÊA, P. M.; MANZINNI, E. J. Protocolo para avaliação de acessibilidade física em escolas da educação infantil. In: SEMINÁRIO NACIONAL DE PESQUISA EM EDUCAÇÃO ESPECIAL, VI, 2011, Nova Almeida. Anais... Nova Almeida: UFES, UFGRS, UFSCar, 2011. 1 CD ROM.

COSTA, G. R. V.; MAIOR, I. M. M. L.; LIMA, N. M. Acessibilidade no Brasil: uma visão histórica. Disponível em: <http://www.prodam.sp.gov.br/multimidia/ $\mathrm{m}$ i d i a / c d_a t i i d / c o n t e u d o / A T I I D $2005 / \mathrm{M} \mathrm{R} 1$ / 01 / AcessibilidadeNoBrasilHistorico.pdf>. Acesso em: 31 mar. 2011.

DUARTE, C. R. S.; COHEN, R. O ensino da arquitetura inclusiva como ferramenta para melhoria da qualidade de vida para todos. In: LARA, F.; MARQUES, S. (Org.). Projetar: desafios e conquistas da pesquisa e do ensino de projeto. Rio de Janeiro: Virtual Científica, 2003. p. 159-173.

$\therefore$. Afeto e lugar: a construção de uma experiência afetiva por pessoas com dificuldades de locomoção. In: SEMINÁRIO ACESSIBILIDADE NO COTIDIANO, 2004, Rio de Janeiro. Anais... Rio de Janeiro: UFRJ, 2004. 1 CD ROM.

Proposta de metodologia de avaliação da acessibilidade aos espaços de Ensino Fundamental. In: SEMINÁRIO INTERNACIONAL DO NÚCLEO DE PESQUISA EM TECNOLOGIADE ARQUITETURAE URBANISMO NUTAU, 2006, São Paulo. Anais... São Paulo: FAUUSP, 2006. 1 CD ROM.

EMMEL, M.L.G.; CASTRO, C. B. Barreiras arquitetônicas no campus universitário: o caso da UFSCar. In: MARQUEZINI, M. C. et al. (Org.). Educação Física, atividades lúdicas e acessibilidade de pessoas com necessidades especiais. Londrina: UEL. 2003, p.177-183. (Coleção Perspectivas Multidisciplinares em Educação Especial, v. 9).

ERHARDT, A. C. A realidade do direito enquanto problema definitório. 2009. Disponível em: <http://jus.uol.com.br/revista/texto/10/a-realidade-do-direitoenquanto-problema-definitorio>. Acesso em: 31 mar. 2011. 
FEIJÓ, A. R. A. O direito constitucional da acessibilidade das pessoas portadoras de deficiência ou com mobilidade reduzida. Rev. da ENA, n. 1, jan. 2008. Disponível em: <http://www.docstoc.com/docs/21959008/O-DIREITO-CONSTITUCIONAL-DA-ACESSIBILIDADE-DAS-PESSOAS-PORTADORAS-DE > . Acesso em: 31 mar. 2011.

FERREIRA, S. L. Ingresso, permanência e competência: uma realidade possível para universitários com necessidades educacionais especiais. Rev. Bras. Ed. Esp., v. 13, n. 1, p. 43-60, jan./abr. 2007.

LAMÔNICA, D. A. C. et al. Acessibilidade em ambiente universitário: identificação de barreiras arquitetônicas no Campus da USP de Bauru. Rev. Bras. Ed. Esp., Marília, v. 14, n. 2, p.177-188, maio/ago. 2008. Disponível em: <http:// www.scielo.br/pdf/rbee/v14n2/03.pdf >. Acesso em: 30 mar. 2009.

LEONARDO, N. S. T.; BRAY, C. T.; ROSSATO, S. P. M. Inclusão escolar: um estudo acerca da implantação da proposta em escolas de ensino básico. Rev. Bras. Educ. Espec., Marília, v. 15, n. 2, p. 289-306, ago. 2009. Disponível em: $<$ http://www.scielo.br/scielo.php?script=sci_arttext\&pid=S141365382009000200008>. Acesso em: 1 abr. 2011.

MANZINI, E. J. et al. Acessibilidade em ambiente universitário: identificação e quantificação de barreiras arquitetônicas. In: MARQUEZINI, M. C. et al. (Org.). Educação Física, atividades lúdicas e acessibilidade de pessoas com necessidades especiais. Londrina: UEL, 2003. p.177-183. (Coleção Perspectivas Multidisciplinares em Educação Especial, v. 9).

.; CORRÊA, P. M. Avaliação da acessibilidade em escolas do Ensino Fundamental usando a tecnologia digital. 2008. Disponível em: <http:// www.anped.org.br/reunioes/31ra/1trabalho/GT15-4331—Int.pdf>. Acesso em: 1 set. 2011.

MARINS, S. C. F.; MATSUKRA, T. S. Avaliação de políticas públicas: a inclusão de alunos com necessidades educacionais especiais no ensino fundamental das cidades-pólo do Estado de São Paulo. Rev. Bras. Ed. Esp., Marília, v.15, n.1, p.45-64, jan.-abr. 2009.

MARTINS FILHO, I. G. S. Os Direitos Fundamentais e os Direitos Sociais na Constituição de 1988 e sua defesa. Rev. Jurídica Virtual, v. 1, n. 4, ago. 1999. Disponível em: <http://www.planalto.gov.br/ccivil_03/revista/rev_04/ direitos_fundamentais.htm>. Acesso em: 7 jun. 2011.

MAZZONI, A. A. et al. Propostas para alcançar a acessibilidade para os portadores de deficiência na biblioteca universitária da UFSC. Rev. ACB., v. 5, n. 5, p. 120-130, 2000. Disponível em: <http://www.revista.acbsc.org.br/index.php/racb/ article/viewFile/352/416>. Acesso em: 1 abr. 2011.

NADER, P. Filosofia do direito. Rio de Janeiro: Forense Universitária, 2001. 
ORGANIZAÇÃO DAS NAÇÕES UNIDAS - ONU. Declaração Universal dos Direitos Humanos. United Nation Information, 1948. Disponível em: <http:// www.onu-brasil.org.br/documentos_direitoshumanos.php>. Acesso em: 31 mar. 2011.

ORGANIZAÇÃO DAS NAÇÕES UNIDAS - ONU. Declaração dos Direitos das Pessoas Deficientes. Assembléia Geral da Organização das Nações Unidas em 09 de novembro de 1975. Disponível em: <http://portal.mec.gov.br/seesp/ arquivos/pdf/dec_def.pdf>. Acesso em: 31 mar. 2011.

PEREIRA, M. M. Inclusão e universidade: análise de trajetórias acadêmicas na Universidade Estadual do Rio Grande do Sul. 2007. 201 f. Dissertação (Mestrado em Educação) - Faculdade de Educação, Universidade Federal do Rio Grande do Sul, Porto Alegre, 2007.

PERINI, T. I. O processo de inclusão no ensino superior em Goiás: a visão dos excluídos. 2006. 121 f. Dissertação (Mestrado em Educação) - Universidade Católica de Goiás, Goiânia, 2006.

PELLEGRINI, C. M. Ingresso, acesso e permanência de alunos com necessidades educacionais especiais na Universidade Federal de Santa Maria - UFSM, RS. 2006. 198 f. Dissertação (Mestrado em Educação), Centro de Educação, Universidade Federal de Santa Maria, Santa Maria, RS, 2006.

RODRIGUES, D. A. Inclusão na universidade: limites e possibilidades da construção de uma universidade inclusiva. Rev. de Educação Especial da UFSM, n. 23, 2004. Disponível em: <http://coralx.ufsm.br/revce/ceesp/2004/01/r1.htm>. Acesso em: 1 abr. 2011.

ROSSETO, E. Sujeitos com deficiência no ensino superior: vozes e significados. 2009. 238 f. Tese (Doutorado em Educação) - Faculdade de Educação da Universidade Federal do Rio Grande do Sul, Porto Alegre, 2009.

ROY, C. Acessibilidade. In: AMBROSI, A.; PEUGEOT, V.; PIMIENTA, D. Desafios de palavras: enfoques multiculturais sobre as sociedades da informação. 2005. Disponível em: <http://vecam.org/article612.html>. Acesso em: 31 mar. 2011.

SANTOS, A. O cego, o espaço, o corpo e o movimento: uma questão de orientação e mobilidade. Rev. Benjamin Constant, 11. ed., mar. 1999. Disponível em: <http://www.ibc.gov.br/?catid=4\&itemid=53>. Acesso em: 1 abr. 2011. 


\section{Notas}

${ }^{1}$ Espaço de comunicação em que não é necessária a presença física do homem para constituir a comunicação como fonte de relacionamento. É o espaço virtual para a comunicação disposto pelo meio de tecnologia.

\section{Correspondência}

Elaine Maria Bessa Rebello Guerreiro - Av. Djalma Batista n. 1035, apt. 12 - Condomínio Vila do Sol Maior, Bairro: Chapada, CEP: 69.050-010, Manaus - AM.

E-mail:em-guerreiro@uol.com.br

Recebido em 02 de dezembro de 2011

Aprovado em 19 de março de 2012 